\title{
Coinfection of Chlamydiae and other Bacteria in Reactive Arthritis and Spondyloarthritis: Need for Future Research
}

\author{
Henning Zeidler ${ }^{1, *}$ and Alan P Hudson ${ }^{2}$ \\ 1 Division of Clinical Immunology and Rheumatology, Hannover Medical School, Hannover 30625, Germany \\ 2 Department of Immunology and Microbiology, Wayne State University School of Medicine, Detroit, \\ MI 48201, USA; ahudson@med.wayne.edu \\ * Correspondence: zeidler.henning@mh-hannover.de \\ Academic Editor: Eberhard Straube \\ Received: 11 July 2016; Accepted: 19 August 2016; Published: 24 August 2016
}

\begin{abstract}
Reactive (inflammatory) arthritis has been known for many years to follow genital infection with the intracellular bacterial pathogen Chlamydia trachomatis in some individuals. Recent studies from several groups have demonstrated that a related bacterium, the respiratory pathogen Chlamydia pneumoniae, can elicit a similar arthritis. Studies of these organisms, and of a set of gastrointestinal pathogens also associated with engendering inflammatory arthritis, have been relatively extensive. However, reports focusing on coinfections with these and/or other organisms, and the effects of such coinfections on the host immune and other systems, have been rare. In this article, we review the extant data regarding infections by multiple pathogens in the joint as they relate to engendering arthritis, and we suggest a number of research areas that must be given a high priority if we are to understand, and therefore to treat in an effective manner, such arthritides.
\end{abstract}

Keywords: Chlamydia trachomatis; Chlamydia pneumoniae; infection; inflammatory arthritis; undifferentiated spondyloarthritides; coinfection

\section{Introduction}

Genital infection by the bacterial pathogen Chlamydia trachomatis (C.tr.) has been known for many years to function as a trigger for Reiter's syndrome (RS) and reactive arthritis (ReA) [1,2]. Recent studies further indicate a chlamydial aetiology even for patients with spondyloarthritis (SpA) $[3,4]$. Epidemiologic data suggest that Chlamydia-induced reactive arthritis (CReA) is a more common condition than previously thought, and that clinicians often fail to recognize it [5,6]. Most importantly, a recent controlled study demonstrated that CReA can be successfully treated with combination antibiotic therapy, thereby raising the possibility of a cure [7,8]. That possibility highlights the increased significance of awareness and diagnosis of arthritis and SpA elicited by Chlamydiae.

It has become clear during the last two decades that two chlamydial species are responsible for causing arthritis, C.tr. and the related respiratory pathogen Chlamydia (Chlamydophila) pneumoniae (C.pn.), and that both elicit the disease via their persistent presence in the joint $[1,2,9,10]$. C.pn. is essentially ubiquitous in all populations so far examined, raising the possibility that coinfection involving the two chlamydial species might be significant in the aetiology of ReA and/or uSpA. This possibility was reinforced by the observation that DNA from a wide variety of bacterial species can be found in the joints of patients with arthritis [11].

Polymicrobial or coinfections are well-known and of demonstrated clinical importance in infectious diseases of the oral cavity, in otitis media, in diabetic foot wound infections, chronic infection in the cystic fibrosis lung, and in other clinical entities [12]. In general, coinfections can be concurrent, as in bacterial pneumonia with Staphylococcus aureus complicating flu infection, or they can 
be closely sequential, as with respiratory viruses plus commensal bacteria such as in otitis media caused by bacterial Streptococcus pneumoniae or Haemophilus influenzae following coronavirus, respiratory syncytial virus, or adenoviral infection [13]. Importantly, in addition to such acute coinfections, chronic infections such as those involving human immunodeficiency virus (HIV) can lead to concurrent bacterial infections with Mycobacterium tuberculosis and other pathogens [13].

Coinfections involving Chlamydia trachomatis (C.tr.) and Neisseria gonorrhoeae have been described often in screening programs and clinical settings; patients with gonorrhoeae also have been reported to have a concurrent chlamydial infection in less than $1 \%$ to a high of $70 \%$ of individuals, thus demonstrating wide variation depending on the population examined. [14-19]. Other coinfections of relevance in urogenital contexts include genital mycoplasmas and genital ureaplasmas. Coinfections with Mycoplasma genitalium or Ureaplasma urealyticum biovar 2 in men with gonococcal urethritis are associated with post-gonococcal urethritis, independent of C.tr. [20]. Additional studies in healthy individuals, in women in a cross-sectional sexual transmission infection (STI) screening program, and in non-gonococcal urethritis and chronic prostatitis, have reported coinfections of C.tr. with M. genitalium, M. hominis, U. urealyticum and U. paroum in urogenital specimens [21-29]. These have been implicated in sexually-transmitted urogenital diseases, although the evidence of the pathogenic role of Ureaplasma species is questionable given its commensal state in the urogenital flora [23,24,27-29].

As mentioned, compelling evidence has accumulated in recent years supporting the causative role of both C.tr. and C.pn. in ReA and spondyloarthritis (SpA) [9]. In this article, we review the evidence for coinfections involving chlamydial species reported in patients with that arthritis and SpA. We discuss the potential aethiopathogenic and clinical implications of such infections, and we address the need for future basic research and clinical studies to improve diagnosis, clinical description, and treatment.

\section{Coinfections with Chlamydiae in Reactive Arthritis and Spondyloarthritis}

Coinfections involving C.tr. and C.pn. were first described in synovial tissue (ST) of patients with reactive arthritis (ReA), Reiter's syndrome (RS), and rheumatoid arthritis (RA), and later also in patients with chronic ReA and undifferentiated spondyloarthritis (uSpA) [3,5,7-9] Most recently, for the first time, multiple intra-articular coinfections of Chlamydiae with Mycoplasma and Ureaplasma were reported in patients with post-venereal ReA [30,31]. As mentioned, during the last two decades it has been established that C.tr. and C.pn. also cause SpA in at least some patients, due to their ability to persist in the joint [2-4]. The epidemiologic prevalence of infection with C.pn. is significantly higher than that for C.tr. overall, an observation which provided a reason for Schumacher and colleagues to assess the incidence of C.pn. DNA compared to that of C.tr. in ST and several synovial fluid (SF) samples from patients with ReA, other arthritides, and in normal joints [9]. Only $12.7 \%$ of the samples $(n=217)$ were positive for C.pn. compared to $28.8 \%$ for C.tr. Importantly, $2.4 \%$ were positive for both organisms; $5.3 \%$ of patients diagnosed with ReA; and $4.7 \%$ diagnosed with RA were PCR-positive for C.pn. DNA. No clear differentiating clinical or other features were identified in the patients positive for both chlamydial species, which is the reason it was not possible to decide which of the two was the causative agent for disease in these cases. Interestingly, genital infection with C.tr. is responsible for eliciting up to half of all cases of ReA, while pulmonary infection with C.pn. is responsible for less than $15 \%$ of cases. The basis for this discrepancy is unknown, but must be related to details of the genetic component of each. However, the elicitation of significant levels of synovial inflammation by either C.tr. or C.pn. does appear to be accomplished by congruent means. That is, transcription of the highly proinflammatory chlamydial hsp60 protein is upregulated during persistent synovial infection in both of these chlamydial species [32,33].

Undifferentiated SpA has been suggested to be a forme fruste of ReA, based on indirect serological evidence of preceding genitourinary or enteric infection [34]. Carter and colleagues investigated the prevalence of C.tr. and/or C.pn. DNA by PCR in ST and peripheral blood monocytes (PBMC) in patients with chronic uSpA $(n=26)$, using patients with osteoarthritis (OA) $(n=167)$ as controls [3]. 
Thirty-eight percent of patients with uSpA were positive in ST and 38\% for C.tr., 15\% for C.pn., and 8\% for both together; OA patients were $11 \%, 0 \%$, and $0.6 \%$ positive, respectively. Only 2 patients with uSpA had a history of possible C.tr. infection, and none had a history of C.pn. infection. PBMC were positive for chlamydial DNA in only 4/26 (15\%) patients with uSpA (3 C.tr.; 1 C.pn.); of those, 2 were positive in ST (1 C.tr.; 1 C.pn.). Together, these data suggested that chlamydial infections, which are often occult for both organisms, are aetiologic for many patients with uSpA. Interestingly, some patients with $\mathrm{OA}$, a degenerative disease without presumed infective aetiology, were found also positive for chlamydial DNA, however, less frequently than those with ReA; this observation clearly suggests that some level of subclinical, essentially invisible, background infection is present in the populations examined.

The question of the role of Chlamydiae as innocent bystander or causative agent in joint disease was investigated in a double-blind, placebo-controlled six-month trial with combination antibiotics (doxycycline $100 \mathrm{mg}$ twice daily and rifampin $300 \mathrm{mg}$ daily, azithromycin $500 \mathrm{mg}$ daily $\times 5$ days then twice weekly and rifampin $300 \mathrm{mg}$ daily). In patients with chronic CReA, all were PCR-positive for C.tr. or C.pn. DNA in PBMCs and/or ST [7]. Sixty-three percent of patients undergoing active treatment were responders compared to $20 \%$ under placebo. Six (22\%) patients undergoing antibiotic treatment experienced complete remission, compared to none in the placebo arm. Most interestingly, $5 / 6$ patients who went into remission were in the azithromycin and rifampin treatment arm, suggesting this combination is most effective. In this study, coinfections of C.tr. plus C.pn. were seen in PBMC in 3 and in ST in 2 patients of the 42 included in the trial. The 2 patients positive for coinfection in $\mathrm{PBMC}$ and who were undergoing combination antibiotic treatment were negative after six months, in contrast to the patient under placebo who remained positive after six months. A recent case report underlines the efficacy of chlamydial coinfection in ReA. A patient (with convincingly demonstrated coinfection-positive culture for C.tr. and C.pn. in SF, culture positive bronchoalveolar lavage (BAL) for C.pn., real time polymerase chain reaction (RT-PCR) positive for both Chlamydia spp. in SF, and RT-PCR positive in BAL for C.pn.) achieved complete remission with the antibiotic combination of azithromycin plus rifampicin for three months, and another two months, after discontinuing of the medications for one month to induce the persistent organisms to return to their active developmental cycle [6].

The results of the controlled trial and the case report are promising and support the causative role of Chlamydiae in arthritis, but those results also engender several questions: (1) Why, in the controlled trial, were about one-third of patients non-responders, and why was the rate of complete remission rather low? (2) Which is the most efficacious combination of antibiotics for treatment, and is there a need to optimize the dosing and duration of therapy? (3) Is it possible that in the controlled trial coinfections involving other bacteria associated with ReA were not identified, which may prevent the response to the treatment regimen?

The latter is an obvious possibility, given the most recent report of multiple coinfections of Chlamydial spp., Mycoplasma, and Ureaplasma in patients with post-venereal ReA [30]. The case study of post-venereal $\operatorname{ReA}(n=22)$ assessed the presence of C.tr., C.pn., M.hominis, and U. urealyticum in samples of ST, SF, and PBMC at the time of synovectomy and after four-month antibiotic combination therapy (a combination of ciprofloxacin, tetracycline, and roxithromycin). Coinfections with two or three different bacteria were detected in 16/22 (72.7\%) patients, most frequently in ST (8/17; 47.1\%; $n=3$ C.tr. plus C.pn., $n=4$ C.tr. plus M. hominis, $n=1$ C.tr. plus C.pn. plus M. hominis) and PBMC (10/22; 45.5\%; $n=6$ C. tr. plus $U$. urealyticum, $n=1$ C.tr. plus C.pn., $n=1$ C. tr. plus M. hominis, $n=2$ C.tr. plus C.pn plus $M$. hominis, $n=1$ C.tr. plus C.pn. plus U. urealyticum) samples [30]. After synovectomy combined with antibiotic combination, C.tr. was found in PBMC samples from 13/22 patients. At diagnosis, 7 patients were positive for C.pn. and 6 for M. hominis. After the therapy, 4 were still positive for C.pn., and one patient remained positive for M. hominis. Before therapy, 9 patients were positive for U. urealyticum, all of whom became negative after therapy. The synovectomy probably contributed 
notably to the remission of patients because the hypertrophic ST containing infectious agents was removed [30].

No intra-articular coinfection of C.tr. and N. gonorrhoeae has been reported to date, to the best of our knowledge, although urogenital coinfections are frequently described. However, other coinfections of Chlamydiae and arthritogenic bacteria are of some relevance. Borrelia burgdorferi is one of the most important arthritis-triggering organisms in western countries and is therefore important in the differential diagnosis of chlamydial arthritis. The simultaneous detection of DNA from C.tr. and B. burgdorferi in the SF of 6 patients with unexplained oligoarthritis was first described by Putschky and colleagues [35]. Coincidental history of tick bite and C.tr. positive in urogenital smears in 2/6 patients, positive serology for both bacteria in 1 patient, and positive B. burgdorferi serology in combination with C.tr. positive in urogenital smears in 1 patient, all support to some extent the suggestion that both bacteria may be causing the joint inflammation in these individual cases. Less convincing is the implicated role of coinfections involving Yersinia enterocolitica, C.pn. and Mycoplasma pneumoniae in Borrelia arthritis, which are based merely on serology and a lymphocyte transformation test [36].

Thus, evidence for coinfections of Chlamydia spp. with one another and with Mycoplasma and/or Ureaplasma species in joints, based on molecular genetic testing, are available for ReA, uSpA, and undifferentiated oligoarthritis from case reports and from case series studies. The pathogenic and clinical implications will be discussed in general in analogy to evidence from other established bacterial coinfections and a few relevant in vitro studies.

\section{Aethiopathogenic and Clinical Implications of Coinfection}

\subsection{Aethopathogenesis}

The traditional reductionist approach of defining details of pathogenesis by studying single bacterial infections in isolation is no longer adequate for understanding that process in polymicrobial/coinfection contexts. This is especially true in anatomic contexts which normally include a complex microbial community, such as the gastrointestinal tract and the oral cavity. The reductionist approach is also inadequate to elucidate pathogenic mechanisms in disease contexts involving complex biofilms [12]. Indeed, the presence of nonpathogenic organisms or opportunistic pathogens at low levels at an anatomic site with one or more pathogens can attenuate pathogenesis, or it can function with the pathogen(s) to increase damage. In many cases, it is simply not possible at present to define with certainty the detailed contribution of each organism (in a coinfection context) to the overall panel of pathogenic features. To cite just one set of examples of the latter from an earlier report from our group, ST and/or SF samples from more than 200 patients with a variety of arthritides were studied using a multiplex PCR system capable of identifying organisms from many genera [11]. Samples chosen for study were known to be PCR-negative for C.tr., C.pn., B. burgdorferi, and several Mycoplasma species, since one purpose of the study was to determine whether bacteria other than those known for eliciting joint disease could be identified in the patients with ReA, RA, OA, psoriatic arthritis, and other diseases. Of the 237 patient DNA samples, 23 (9.7\%) were PCR-positive, all but 2 of which were ST. Organisms identified via DNA sequence analysis of the generated PCR products included those from the genera Pseudomonas, Moraxella, Acinetobacter, Salmonella, and others; 8/23 PCR-positive samples proved to be multiply infected, with organisms from the genera Xanthomonas, Stenotrophomonas, Enterobacter, and others identified in addition to the relevant index organism. We could not identify any specific aspect of synovial pathogenesis that was attributable to either of the organisms in the multiply infected samples. Here we will not address issues relating to or resulting from biofilm formation or infection of normal complex microbiological communities in human. Because only limited data regarding coinfection in ST and/or SF samples from ReA, SpA or other relevant patients are available currently, we will explore the effects of coinfection on relevant and other organisms and/or the host immune response to them, in in vitro systems or in vivo animal model systems. One set of such studies was published by our group a number of years ago. The first was intended to examine the effect of 
mycoplasma contamination on cultures of C.tr. and C.pn., with the goal of clearing those cultures of the contaminating organisms [37]. Five of 9 C.tr. (both genital and trachoma strains) and 5/16 C.pn. isolates were confirmed to include mycoplasma contamination, and restriction analyses plus selective DNA sequencing of $16 S$ rRNA produced by PCR identified M. hominis, M. fermentans, and M. hyorhinis in those isolates. Growth of both C.tr. and C.pn. in culture was substantially inhibited in cultures using the isolates contaminated with the various Mycoplasma species, compared to growth in cultures seeded with non-Mycoplasma-containing strains. It was not clear what effect synovial coinfection with Chlamydiae and Mycoplasmae might have on disease induction or duration, but the speculation was put forth that both might be made worse if the host immune response to Chlamydiae was attenuated in that situation. In a related study of C.pn. and C.tr. infection of human monocytes in culture, prostaglandin E2 $\left(\mathrm{PGE}_{2}\right)$ production was demonstrated to be induced, although such production was not as high as that induced by treatment of the monocytes with lipopolysaccharide (LPS) from E. coli [38]. Interestingly, production of $\mathrm{PGE}_{2}$ was higher in cultured monocytes infected with C.tr. compared to similar cultures infected with C.pn., but when cultures were infected with strains/isolates of either chlamydial species along with $M$. fermentans, $\mathrm{PGE}_{2}$ production was increased in a synergistic manner. Thus, coinfection of human cells in culture with either chlamydial species plus Mycoplasmae affects not only growth of Chlamydiae but also the host response to that infection.

Studies from another group investigated a relationship between coinfection with C.tr. and Ureaplasma paroum, the latter a common commensal in the human female genital system [39]. Treatment of Chlamydia-infected cultures of HeLa, HEp-2, or other cell types with IFN- $\gamma$ results in intracellular Chlamydiae transiting to the persistent infection state $[1,5,10,40]$. Coinfection of C.tr. and $U$. parvum released C.tr. in infected, IFN- $\gamma$-treated HeLa cells from persistence; however, in the absence of IFN- $\gamma$ the presence of $U$. parvum attenuated chlamydial growth. In host HeLa cells, IFN- $\gamma$ inhibits tryptophan production via induction of the enzyme indoleamine 2,3-dioxygenase (IDO), and this amino acid is a requirement for intracellular growth and maturation of C.tr. [41]. In $U$. parvum-/IFN- $\gamma$-treated cultures of C.tr.-infected Hela cells, presence of the former organism either in viable or heat-killed form had no effect on IDO gene expression or enzyme production.

A recent review described studies of respiratory system coinfection with Streptococcus pneumoniae and other common human pathogens [42]. This is of particular interest because the organisms at issue are mucosal pathogens, as are C.tr. and C.pn.; synovial pathogenesis is a sequela of prior mucosal infection with either of the latter organisms. Coinfection with S. pneumoniae and Haemophilus influenza is common in most populations studied, particularly in children. In in vitro co-culture studies, the former has repeatedly demonstrated a clear growth and fitness advantage over the latter, but the converse is true in coinfection studies in a murine model. Investigation of the mechanism of this in vivo effect implicates a complex modulation of the host immune response, which results in a selection for virulent S. pneumoniae strains. Conversely, during coinfection with S. pneumoniae and S. aureus, the former strongly attenuates carriage of the latter, probably also via an immune-mediated mechanism. During coinfection with S. pneumoniae and influenza virus, the latter attenuates immune suppression of the bacterium, engendering a synergism in pathogenesis between the two. Thus, the interaction of multiple pathogens at the mucosal surface is a complex process, the outcome of which, in terms of pathogenesis, is not a combinatorial result of individual pathogenic mechanisms.

An issue of interest is the observation of post-gonococcal ReA suggestive of chlamydial aetiology due to urogenital coinfection of C.tr. and Neisseria gonorrhoeae but missing confirmation of the intra-articular coinfection. There are several possible explanations for that lack: (1) No targeted search in joint samples in the acute phase of gonococcal arthritis and/or post-gonococcal arthritis. Only one study searched for Chlamydia, Ureaplasma, and Neisseria DNA in SF from patients with inflammatory arthritis $(n=61)$, including a small number clinically associated with venereal infection ( $n=5$ gonococcal arthritis, $n=5 \mathrm{RS} / \mathrm{ReA}$ ) with no observation of coinfection [43]. One patient with gonococcal arthritis was diagnosed because of SF-positivity by PCR for Neisseria DNA; proven Chlamydia cervicitis was negative for coinfection with C.tr. in the joint [43]. (2) N. gonorrhoeae itself may 
induce an aseptic ReA in susceptible patients who are treated with penicillin early and adequately, allowing the gonococci to survive in the accessory glands or the oviducts; this hypothesis was suggested on the basis of similar clinical pattern compared with RS and greater lymphocyte stimulation induced by gonococcal antigen, which was more significant in patients with post-gonorrhoeal aseptic arthritis than in healthy controls [44]. (3) The antibiotic regime against gonococci does not simultaneously eradicate coincident chlamydial infection, which allows Chlamydia to invade the inflamed joint by dissemination from the urogenital reservoir.

\subsection{Diagnostic Implications}

The diagnosis of ReA is most commonly based on the history of preceding infection, urogenital testing for C.tr., and serology for antibodies against arthritogenic bacteria. It is rare that ST and SF samples are available for molecular testing targeting bacterial DNA in research or clinical laboratories; no commercial test kits are approved for routine application in the rheumatological setting. Thus, there is a pressing need to address the diagnostic identification of coinfections in arthritis:

(1). First, a research initiative is needed to investigate patients with undifferentiated arthritis, ReA, and undifferentiated SPA for intra-articular coinfections involving Chlamydiae and urogenital Mycoplasma and Ureaplasma spp.; the aim is to confirm the finding mentioned above in post-venereal ReA, which to date has been reported in only in one research unit, and to expand the investigation to the entire spectrum of arthritides which are potential consequences of coinfections.

(2). It will also be of interest to determine whether other coinfections may be found (e.g., Chlamydia plus enteric bacteria) with $M$. pneumoniae, M. fermentans, M. salivarium and M. arthritides which have been implicated as causative agents of arthritis, and whose DNA have been found by PCR in the SF of divers' joint diseases [45-49] Of note, a recent study reported coinfections of M. pneumoniae, M. hominis, and $M$. arthritides in SF samples of patients with RA, using a multiplex PCR method developed for rapid and simultaneous identification of these species [50].

(3). The development of sensitive and specific multiplex molecular testing methods will be necessary to address the topics raised here, since in contrast to septic arthritis the number of non-culturable bacteria found in the joints of patients with chlamydial and other $\operatorname{ReA}$ is usually quite low. In our experience DNA extraction methods and PCR protocols must be adapted to the SF and ST milieu to reach adequate levels of performance [51-54]. We assume that research laboratories will develop and test protocols designed for use with joint samples for the identification of Mycoplasma, Ureaplasma, and enteric. This approach was applied to the simultaneous detection of Mycoplasma spp. in SF samples from patients with RA by multiplex PCR [50].

(4). Translation of research protocols and data into clinical practise requires the development of commercially available test kits adapted for SF analyses. The Anyplex II STI-7 kit (STI-7, Seegene, Eurobio)—-marketed to simultaneously detect C.tr., Mycoplasma spp., and Ureaplasma spp. involved in sexually transmitted infections-has identified coinfections in patients screened for genital infection and thus gives promise that the development of multiplex RT-PCR assay for the use in rheumatic patients can be realized [55]. Adaption for joint samples will be needed; our earlier observations demonstrated that commercial assays developed for urogenital samples allow the detection of C.tr. in clinical specimens, but they do so with a lower sensitivity than do our in-house developed omp1-specific PCR in concert with optimised sample preparation of SF [56].

(5). Chlamydiae are disseminated in monocytes/macrophages from the original site of infection by peripheral blood. They settle into the joint as shown by demonstration of chlamydial DNA in PBMC preparations from patients with ReA and undifferentiated SpA [3,57]. Hence, an important additional research topic centres on investigation of peripheral blood for detectable coinfections in patients with arthritis. The development of commercial multiplex PCR assays for peripheral blood testing is of great importance for rapid diagnosis, and to overcome the limited availability of joint samples in every day clinical practise. 
The comprehensive research program outlined here is a prerequisite to understand the clinical implication of chlamydial coinfections in arthritis and SpA, and to develop therapeutic strategies directed against multiple persistently-infecting organisms.

\subsection{Clinical Implication}

The disease course of ReA is self-limiting, remitting, or chronic progressive. A few factors are known to be associated with the progression from acute ReA to chronic SpA: the presence of HLA-B27, a positive family history for ankylosing spondylitis or $\mathrm{SpA}$, and the presence of chronic lesions in the gut [58]. One can envision several scenarios explaining how coinfections might impact CReA:

(1). Coinfections may induce more severe inflammation in the arthritic joint during the acute phase of disease, and/or.

(2). They may prolong the self-limiting phase of the disease, and/or.

(3). They may cause relapse of the disease, and/or.

(4). They may support the chronic disease course because one or several of the coinfecting bacteria are not eliminated.

In vitro studies have shown that coinfections of M. fermentans with C.tr. and C.pn. suppress chlamydial growth, which in turn may induce persistent infection resulting in additive stimulation of the $\mathrm{PGE}_{2}$ production in human monocytes $[37,38]$. Elicitation of chlamydial persistence by either species in the synovium via whatever means virtually guarantees significant and sustained levels of local inflammation. As given in detail in other publications, persistently infecting Chlamydiae display a number of unusual morphological and molecular genetic characteristics, all of which contribute to production of inflammation in the host. Morphology for persistent C.tr. and C.pn. both is highly aberrant, a reflection of the severe attenuation of production of the immunodominant, shape-determining major outer membrane protein (omp-1) of these organisms. This selective transcriptional attenuation is just one facet of a major adjustment in the overall panel of chlamydial gene expression which characterises persistence. As mentioned above, probably the most critical adjustment relevant to inflammation is the strong upregulation of expression of the bacterial heat shock protein-encoding (hsp) genes, the products of which are recognized by the host as powerfully proinflammatory [32,33]. Other molecular genetic aspects of persistence also contribute variously to induction and maintenance of inflammation [10,59-61]. All these effects are factors that may cause more severe, prolonged, and even chronic disease. Further and as described above, coinfection with C.tr. and $U$. parvum in an in vitro HeLa cell system treated with IFN- $\gamma$ promotes maturation of C.tr. from reticulate bodies to elementary bodies independent of IDO expression; clearly this suggests a novel survival strategy of C.tr. against IFN- $\gamma$ exposure, which is of course a critical host defence factor for eliminating Chlamydiae [39].

\subsection{Treatment}

As already mentioned, the question arises as to why, in the double-blind, placebo-controlled six-month trial with combination antibiotics (doxycycline $100 \mathrm{mg}$ twice daily and rifampin $300 \mathrm{mg}$ daily, azithromycin $500 \mathrm{mg}$ daily $\times 5$ days then twice weekly and rifampin $300 \mathrm{mg}$ daily) in patients with chronic CReA [7], about one-third of patients were non-responders, and why the rate of complete remission was rather low. Supposing that coinfections involving other bacteria associated with ReA were not identified, in that case, the effectiveness of the antibiotics against the candidate bacteria must be questioned. For example, doxycycline effectively has a low eradication rate for M. genitalium, and the eradication rate with azithromycin is decreased significantly due to rapid emergence of resistance [62]. A 5 day azithromycin treatment regimen $-500 \mathrm{mg}$ on day 1 and $250 \mathrm{mg}$ on the following 4 days-is needed to effectively eradicate urogenital coinfections of C.tr. and M. genitalium. This may explain why the combination of azithromycin and rifampin was most effective in inducing remission in chronic $\mathrm{CReA}$, although chlamydial infection alone can be effectively eliminated by the combination of azithromycin and rifampin in vitro in HEp-2 cells [63]. In summary, further studies are necessary to 
identify the most effective antimicrobial combination therapy, including that for coinfections, to cure chlamydial arthritis.

\section{Conclusions}

Several recent reports of coinfections cited herein involving Chlamydiae, M. hominis, and U. urealyticum in patients with post-venereal ReA indicate a clear and critical unmet need for future research to understand the nature and consequences of coinfections for diagnostics, clinical course, and treatment of chlamydial arthritis and SpA. In particular, more holistic data collection-including the large spectrum of the potential urogenital, respiratory, and even enteric pathogen candidates for coinfections-would help to advance understanding of the role of bacteria in arthritis and SpA. Improved knowledge is needed regarding the risk factors for coinfections, the clinical circumstances in which Chlamydiae interact with other pathogens, and the mechanisms behind such pathogen-pathogen interactions, including experimental studies.

Acknowledgments: A.P.H. had no sources of funding which provided any support for the preparation of this article.

Author Contributions: Both authors contributed equally to the writing and overall preparation of this article. Both provided intellectual input to the sense and conclusions of the paper, and both authors have agreed to the final version of the submitted manuscript.

Conflicts of Interest: The authors declare no conflict of interest.

\section{References}

1. Zeidler, H.; Kuipers, J.; Köhler, L. Chlamydia-induced arthritis. Curr. Opin. Rheumatol. 2004, 16, $380-392$. [CrossRef] [PubMed]

2. Carter, J.D.; Hudson, A.P. The evolving story of Chlamydia-induced reactive arthritis. Curr. Opin. Rheumatol. 2010, 22, 424-430. [CrossRef] [PubMed]

3. Carter, J.D.; Gerard, H.C.; Espinoza, L.; Ricca, L.; Valeriano, J.; Snelgrove, J.; Oszust, C.; Vasey, F.B.; Hudson, A.P. Chlamydiae as etiologic agents for chronic undifferentiated spondyloarthropathy. Arthritis Rheum. 2009, 60, 1311-1316. [CrossRef] [PubMed]

4. Zeidler, H.; Hudson, A.P. Causality of Chlamydiae in arthritis and spondyloarthritis: A plea for increased translational research. Curr. Rheumatol. Rep. 2016, 18, 9. [CrossRef] [PubMed]

5. Carter, J.D.; Inman, R.D.; Hudson, A.P. Chlamydia and chronic arthritis. Ann. Med. 2012, 44, 784-792. [CrossRef] [PubMed]

6. Rizzo, A.; Domenico, M.D.; Carratelli, C.R.; Paolillo, R. The role of Chlamydia and Chlamydophila infections in reactive arthritis. Intern. Med. 2012, 51, 113-117. [CrossRef] [PubMed]

7. Carter, J.D.; Espinoza, L.R.; Inman, R.D.; Sneed, K.B.; Ricca, L.R.; Vasey, F.B.; Valeriano, J.; Stanich, J.A.; Oszust, C.; Gerard, H.C.; et al. Combination antibiotics as a treatment for chronic Chlamydia-induced reactive arthritis: A double-blind, placebo-controlled, prospective trial. Arthritis Rheum. 2010, 62, 1298-1307. [CrossRef] [PubMed]

8. Zeidler, H.; Hudson, A.P. New insights into Chlamydia and arthritis: Promise of a cure? Ann. Rheum. Dis. 2014, 73, 637-644. [CrossRef] [PubMed]

9. Schumacher, H.R.; Gérard, H.C.; Arayssi, T.K.; Pando, J.A.; Branigan, P.J.; Saaibi, D.L.; Hudson, A.P. Lower prevalence of Chlamydia pneumoniae DNA compared with Chlamydia trachomatis DNA in synovial tissue of arthritis patients. Arthritis Rheum. 1999, 42, 1889-1893. [CrossRef]

10. Villareal, C.; Whittum-Hudson, J.A.; Hudson, A.P. Persistent Chlamydiae and chronic arthritis. Arthritis Res. 2002, 4, 5-9. [CrossRef] [PubMed]

11. Gérard, H.C.; Wang, Z.; Wang, G.F.; El-Gabalawi, H.; Goldbach-Mansky, R.; Li, Y.; Majeed, W.; Zhang, H.; Ngai, N.; Schumacher, H.R.; et al. Chromosomal DNA from a variety of bacterial species is present in synovial tissue in patients with various forms of arthritis. Arthritis Rheum. 2001, 44, 1689-1697. [CrossRef]

12. Peters, B.M.; Jabra-Rizk, M.A.; O’May, G.A.; Costerton, J.W.; Shirtliff, M.E. Polymicrobial interactions: Impact on pathogenesis and human disease. Clin. Microbiol. Rev. 2012, 25, 193-213. [CrossRef] [PubMed]

13. Pasman, L. The complication of coinfection. Yale J. Biol. Med. 2012, 85, 127-132. [PubMed] 
14. Vonck, R.A.; Darville, T.; O'Connell, C.M.; Jerse, A.E. Chlamydial infection increases gonococcal colonization in a novel murine coinfection model. Infect. Immun. 2011, 79, 1566-1577. [CrossRef] [PubMed]

15. Creighton, S.; Tenant-Flowers, M.; Taylor, C.B.; Miller, R.; Low, N. Coinfection with gonorrhoea and Chlamydia: How much is there and what does it mean? Int. J. STD AIDS 2003, 14, 109-113. [CrossRef] [PubMed]

16. Dragovic, B.; Greaves, K.; Vashisht, A.; Straughair, G.; Sabin, C.; Smith, N.A. Chlamydial co-infection among patients with gonorrhoea. Int. J. STD AIDS 2002, 13, 261-263. [CrossRef] [PubMed]

17. Forward, K.R. Risk of coinfection with Chlamydia trachomatis and Neisseria gonorrhoeae in Nova Scotia. Can. J. Infect. Dis. Med. Microbiol. 2010, 21, e84-e86. [PubMed]

18. Van Bergen, J.E.; Spaargaren, J.; Götz, H.M.; Veldhuijzen, I.K.; Bindels, P.J.; Coenen, T.J.; Broer, J.; de Groot, F.; Hoebe, C.J.; Richardus, J.H.; et al. Population prevalence of Chlamydia trachomatis and Neisseria gonorrhoeae in the Netherlands. should asymptomatic persons be tested during Population-based Chlamydia Screening also for gonorrhoea or only if chlamydial infection is found? BMC Infect. Dis. 2006, 6. [CrossRef] [PubMed]

19. McMillan, A.; Manavi, K.; Young, H. Concurrent gonococcal and chlamydial infections among men attending a sexually transmitted diseases clinic. Int. J. STD AIDS 2005, 16, 357-361. [PubMed]

20. Yokoi, S.; Maeda, S.; Kubota, Y.; Tamaki, M.; Mizutani, K.; Yasuda, M.; Nakano, M.; Ehara, H.; Deguchi, T. The role of Mycoplasma genitalium and Ureaplasma urealyticum biovar 2 in postgonococcal urethritis. Clin. Infect. Dis. 2007, 45, 866-871. [CrossRef] [PubMed]

21. Campos, G.B.; Lobão, T.N.; Selis, N.N.; Amorim, A.T.; Martins, H.B.; Barbosa, M.S.; Oliveira, T.H.; dos Santos, D.B.; Figueiredo, T.B.; MIranda Marques, L.; et al. Prevalence of Mycoplasma genitalium and Mycoplasma hominis in urogenital tract of Brazilian women. BMC Infect. Dis. 2015, 15. [CrossRef] [PubMed]

22. Mobley, V.L.; Hobbs, M.M.; Lau, K.; Weinbaum, B.S.; Getman, D.K.; Seña, A.C. Mycoplasma genitalium infection in women attending a sexually transmitted infection clinic: Diagnostic specimen type, coinfections, and predictors. Sex. Transm. Dis. 2012, 39, 706-709. [CrossRef] [PubMed]

23. Horner, P.; Thomas, B.; Gilroy, C.B.; Egger, M.; Taylor-Robinson, D. Role of Mycoplasma genitalium and Ureaplasma urealyticum in acute and chronic nongonococcal urethritis. Clin. Infect. Dis. 2001, 32, 995-1003. [CrossRef] [PubMed]

24. Maeda, S.; Deguchi, T.; Ishiko, H.; Matsumoto, T.; Naito, S.; Kumon, H.; TsUKamoto, T.; Onodera, S.; Kamidono, S. Detection of Mycoplasma genitalium, Mycoplasma hominis, Ureaplasma parvum (biovar 1) and Ureaplasma urealyticum (biovar 2) in patients with non-gonococcal urethritis using polymerase chain reaction-microtiter plate hybridization. Int. J. Urol. 2004, 11, 750-754. [CrossRef] [PubMed]

25. Huppert, J.S.; Mortensen, J.E.; Reed, J.L.; Kahn, J.A.; Rich, K.D.; Hobbs, M.M. Mycoplasma genitalium detected by transcription-mediated amplification is associated with Chlamydia trachomatis in adolescent women. Sex. Transm. Dis. 2008, 5, 250-254. [CrossRef] [PubMed]

26. Berle, L.M.; Firsova, N.; Kalashnik, A.; Protasova, V.M.; Ponomareva, Z.V.; GuBernickaya, S.V.; Kudrina, T.I.; Haaheim, H.; Hjelmevoll, S.O.; Skogen, V. Chlamydia trachomatis, Mycoplasma genitalium and Ureaplasma urealyticum in clinical and non-clinical settings, Arkhangelsk Oblast, Russia. Int. J. STD AIDS 2012, 23, 781-784. [CrossRef] [PubMed]

27. Jensen, A.J.; Kleveland, C.R.; Moghaddam, A.; Haaheim, H.; Hjelmevoll, S.O.; Skogen, V. Chlamydia trachomatis, Mycoplasma genitalium and Ureaplasma urealyticum among students in Northern Norway. J. Eur. Acad. Dermatol. Venereol. 2013, 27, e91-e96. [CrossRef] [PubMed]

28. Hunter, J.M.; Young, H.; Harris, A.B. Genitourinary infection with Ureaplasma urealyticum in women attending a sexually transmitted diseases clinic. Br. J. Vener. Dis. 1981, 57, 338-342. [PubMed]

29. Brunner, H.; Weidner, W.; Schiefer, H.G. Quantitative studies on the role of Ureaplasma urealyticum in non-gonococcal urethritis and chronic prostatitis. Yale J. Biol. Med. 1983, 56, 545-550. [PubMed]

30. Strelić, N.; Bojović, J.; Pavlica, L.; Cikota-Aleksić, B.; Miličić, B.; Magić, Z. Detection of bacteria and analyses of Chlamydia trachomatis viability in patients with postvenereal reactive arthritis. Intern. Med. J. 2014, 44, 1247-1251. [CrossRef] [PubMed]

31. Bojović, J.; Strelić, N.; Pavlica, L. Reiter's syndRome-Disease of young men-analysis of 312 patients. Med. Pregl. 2014, 67, 222-230. [CrossRef] [PubMed]

32. Gérard, H.C.; Whittum-Hudson, J.A.; Schumacher, H.R.; Hudson, A.P. Differential expression of the three Chlamydia trachomatis hsp60-encoding genes in active vs persistent infection. Microb. Pathog. 2004, 36, 35-39. [CrossRef] [PubMed] 
33. Contini, C.; Grilli, A.; Badia, L.; Guardigni, V.; Govoni, M.; Seraceni, S. Detection of Chlamydophila pneumoniae in patients with arthritis: Significance and diagnostic value. Rheumatol. Int. 2011, 31, 1307-1313. [CrossRef] [PubMed]

34. Aggarwal, A.; Misra, R.; Chandrasekhar, S.; Prasad, K.N.; Dayal, R.; Ayyagari, A. Is undifferentiated seronegative spondyloarthropathy a forme fruste of reactive arthritis? Br. J. Rheumatol. 1997, 36, 1001-1004. [CrossRef] [PubMed]

35. Putschky, N.; Schnarr, S.; Wollenhaupt, J.; Zeidler, H.; Kuipers, J.G. Intra-articular co-infection by Borrelia burgdorferi and Chlamydia trachomatis. Ann. Rheum. Dis. 2001, 60, 632-634. [CrossRef] [PubMed]

36. Berghoff, W. Chronic lyme disease and co-infections: Differential diagnosis. Open Neurol. J. 2012, 6, 158-178. [CrossRef] [PubMed]

37. Krausse-Opatz, B.; Dollmann, P.; Zeidler, H.; Köhler, L.; Kuipers, J.G. Mycoplasma fermentans, M. hominis, and M. hyorhinis inhibit infectivity and growth of Chlamydia trachomatis and C. pneumoniae in HEp-2 cells. J. Clin. Microbiol. 2000, 38, 3910-3911. [PubMed]

38. Krausse-Opatz, B.; Fendrich, U.; Bialowons, A.; Kaever, V.; Zeidler, H.; Kuipers, J.; Köhler, L. Production of prostaglandin $\mathrm{E}_{2}$ in monocytes stimulated in vitro by Chlamydia trachomatis, Chlamydophila pneumoniae, and Mycoplasma fermentans. Microb. Pathog. 2004, 37, 155-161. [CrossRef] [PubMed]

39. Yamazaki, T.; Matsuo, J.; Nakamura, S.; Oguri, S.; Yamaguchi, H. Effect of Ureaplasma parvum co-inCubation on Chlamydia trachomatis maturation in human epithelial HeLa cells treated with interferon-y. J. Infect. Chemother. 2014, 20, 460-464. [CrossRef] [PubMed]

40. Whittum-Hudson, J.A.; Hudson, A.P. Human chlamydial infections: Persistence, prevalence, and prospects for the future. Nat. Sci. Soc. 2005, 13, 371-382. [CrossRef]

41. Abdelrahman, Y.M.; Belland, R.J. The chlamydial developmental cycle. FEMS Microbiol. Rev. 2005, 29, 949-959. [CrossRef] [PubMed]

42. Lijek, R.S.; Weiser, J.N. Coinfection subverts mucosal immunity in the upper respiratory tract. Curr. Opin. Immunol. 2012, 224, 417-423. [CrossRef] [PubMed]

43. Li, F.; Bulbul, R.; Schumacher, H.R., Jr.; Kieber-Emmons, T.; Callegari, P.E.; von Feldt, J.M.; Norden, D.; Freundlich, B.; Wang, B.; Imonitie, V.; et al. Molecular detection of bacterial DNA in venereal-associated arthritis. Arthritis Rheum. 1996, 39, 950-958. [CrossRef] [PubMed]

44. Rosenthal, L.; Olhagen, B.; Ek, S. Aseptic arthritis after gonorrhoea. Ann. Rheum. Dis. 1980, 39, $141-146$. [CrossRef] [PubMed]

45. Hakkarainen, K.; Turunen, H.; Miettinen, A.; Karppelin, M.; Kaitila, K.; Jansson, E. Mycoplasmas and arthritis. Ann. Rheum. Dis. 1992, 51, 1170-1172. [CrossRef] [PubMed]

46. Haier, J.; Nasralla, M.; Franco, A.R.; Nicolson, G.L. Detection of mycoplasmal infections in blood of patients with rheumatoid arthritis. Rheumatology 1999, 38, 504-509. [CrossRef] [PubMed]

47. Johnson, S.; Sidebottom, D.; Bruckner, F.; Collins, D. Identification of Mycoplasma fermentans in synovial fluid samples from arthritis patients with inflammatory disease. J. Clin. Microbiol. 2000, 38, 90-93. [PubMed]

48. Gilroy, C.B.; Keat, A.; Taylor-Robinson, D. The prevalence of Mycoplasma fermentans in patients with inflammatory arthritides. Rheumatology 2001, 40, 1355-1358. [CrossRef] [PubMed]

49. Johnson, S.M.; Bruckner, F.; Collins, D. Distribution of Mycoplasma pneumoniae and Mycoplasma salivarium in the synovial fluid of arthritis patients. J. Clin. Microbiol. 2007, 45, 953-957. [CrossRef] [PubMed]

50. Ataee, R.A.; Golmohammadi, R.; Alishiri, G.H.; Mirnejad, R.; Najafi, A.; Esmaeili, D.; Jonaidi-Jafari, N. Simultaneous detection of Mycoplasma pneumoniae, Mycoplasma hominis, and Mycoplasma arthritidis in synovial fluid of patients with rheumatoid arthritis by multiplex PCR. Arch. Iran. Med. 2015, 18, 345-350. [PubMed]

51. Kuipers, J.G.; Nietfeld, L.; Dreses-Werringloer, U.; Koehler, L.; Wollenhaupt, J.; Zeidler, H.; Hammer, M. Optimised sample preparation of synovial fluid for detection of Chlamydia trachomatis DNA by polymerase chain reaction. Ann. Rheum. Dis. 1999, 58, 103-108. [CrossRef] [PubMed]

52. Freise, J.; Gérard, H.C.; Bunke, T.; Whittum-Hudson, J.A.; Zeidler, H.; Köhler, L.; Hudson, A.P.; Kuipers, J.G. Optimised sample DNA preparation for detection of Chlamydia trachomatis in synovial tissue by polymerase chain reaction and ligase chain reaction. Ann. Rheum. Dis. 2001, 60, 140-145. [CrossRef] [PubMed]

53. Freise, J.; Bernau, I.; Meier, S.; Zeidler, H.; Kuipers, J.G. Detection of Chlamydia trachomatis DNA in synovial fluid: Evaluation of the sensitivity of different DNA extraction methods and amplification systems. Arthritis Res. Ther. 2009, 11. [CrossRef] [PubMed] 
54. Freise, J.; Bernau, I.; Meier, S.; Zeidler, H.; Kuipers, J.G. Optimized testing for C. trachomatis DNA in synovial fluid samples in clinical practice. Z Rheumatol. 2015, 74, 824-828. [CrossRef] [PubMed]

55. Berçot, B.; Amarsy, R.; Goubard, A.; Aparicio, C.; Loeung, H.U.; Segouin, C.; Gueret, D.; Jacquier, H.; Meunier, F.; Mougari, F.; et al. Assessment of coinfection of sexually transmitted pathogen microbes by use of the anyplex II STI-7 molecular kit. J. Clin. Microbiol. 2015, 53, 991-993.

56. Kuipers, J.G.; Andresen, J.; Köhler, L.; Schnarr, S.; Putschky, N.; Zeidler, H.; Wollenhaupt, J. Evaluation of amplicor Chlamydia PCR and LCX Chlamydia LCR to detect Chlamydia trachomatis in synovial fluid. Clin. Exp. Rheumatol. 2002, 20, 185-192. [PubMed]

57. Kuipers, J.G.; Jürgens-Saathoff, B.; Bialowons, A.; Wollenhaupt, J.; Köhler, L.; Zeidler, H. Detection of Chlamydia trachomatis in peripheral blood leukocytes of reactive arthritis patients by polymerase chain reaction. Arthritis Rheum. 1998, 41, 1894-1895. [CrossRef]

58. Hannu, T.; Inman, R.; Granfors, K.; Leirisalo-Repo, M. Reactive arthritis or post-infectious arthritis? Best Pract. Res. Clin. Rheumatol. 2006, 20, 419-433. [CrossRef] [PubMed]

59. Gérard, H.C.; Whittum-Hudson, J.A.; Schumacher, H.R.; Hudson, A.P. Synovial Chlamydia trachomatis up-regulates expression of a panel of genes similar to that transcribed by Mycobacterium tuberculosis during persistent infection. Ann. Rheum. Dis. 2006, 65, 321-327.

60. Gérard, H.C.; Whittum-Hudson, J.A.; Carter, J.D.; Hudson, A.P. Molecular biology of infectious agents in chronic arthritis. Rheum. Dis. Clin. North Am. 2009, 35, 1-19. [CrossRef] [PubMed]

61. Carter, J.D.; Gerard, H.C.; Whittum-Hudson, J.A.; Hudson, A.P. The molecular basis for disease phenotype in chronic Chlamydia-induced arthritis. Int. J. Clin. Rheum. 2012, 7, 627-640. [CrossRef] [PubMed]

62. Unemo, M.; Endre, K.M.; Moi, H. Five-day azithromycin treatment regimen for Mycoplasma genitalium infection also effectively eradicates Chlamydia trachomatis. Acta. Derm. Venereol. 2015, 95, 730-732. [CrossRef] [PubMed]

63. Dreses-Werringloer, U.; Padubrin, I.; Zeidler, H.; Kohler, L. Effects of azithromycin and rifampin on Chlamydia trachomatis infection in vitro. Antimicrob. Agents Chemother. 2001, 45, 3001-3008. [CrossRef] [PubMed]

(C) 2016 by the authors; licensee MDPI, Basel, Switzerland. This article is an open access article distributed under the terms and conditions of the Creative Commons Attribution (CC-BY) license (http://creativecommons.org/licenses/by/4.0/). 